\title{
Sediment Microstructure and the Establishment of Gas Migration Pathways during Bubble Growth
}

\author{
Michael Johnson, ${ }^{\dagger}$ (๖ Jeffrey Peakall, ${ }^{\ddagger}$ Michael Fairweather, ${ }^{\dagger}$ Martyn Barnes, ${ }^{\S}$ Sushma Davison, ${ }^{\S}$ \\ Xiaodong Jia, ${ }^{\dagger}$ Michael A. Clare, ${ }^{\|}$David Harbottle, ${ }^{\dagger}$ and Timothy N. Hunter*, ${ }^{\dagger}$ \\ ${ }^{\dagger}$ School of Chemical and Process Engineering and ${ }^{\ddagger}$ School of Earth and Environment, University of Leeds, Leeds LS2 9JT, U.K. \\ ${ }^{\S}$ Sellafield Ltd., Hinton House, Birchwood Park Ave, Birchwood, Warrington WA3 6GR, U.K. \\ "National Oceanography Centre, European Way, Southampton SO14 3ZH, U.K.
}

Supporting Information

\begin{abstract}
Soft sediments exhibit complex and varied deformation behavior during in situ bubble growth; however, the sediment microstructure is often neglected when predicting bubble networking or fracture propagation dynamics. This study considers three chemically similar $\mathrm{Mg}(\mathrm{OH})_{2}$-rich sediments, which differ slightly in their particle size distributions and morphologies but exhibit significant differences in their porosity, stiffness, and pore throat dimensions at equivalent yield strengths. At low yield strengths, microstructure greatly influenced the size distribution and connectivity of spherical bubble populations, with narrow sedimentary pore throats promoting coarser bubbles

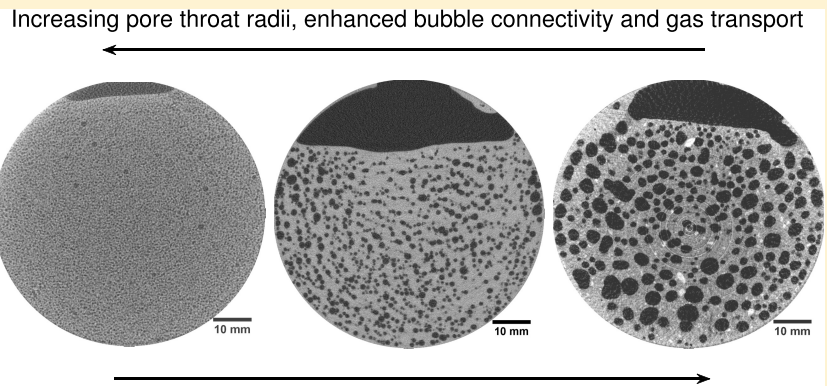

Smaller populations of larger bubbles with diminished connectivity. Increased connectivity of the bubble population appeared highly significant in limiting bed expansion, either by establishing pathways for gas release or by dissipating excess internal bubble pressure, thereby diminishing further growth. During in situ gas generation, each sediment demonstrated a critical fracture strength, which demarcated the populations with high void fractions $(0.27<\nu<0.4)$ of near-spherical bubbles from a fracturing regime supporting reduced void fractions $(\nu \approx 0.15)$ of high aspect ratio cracks. However, critical fracture strengths varied significantly (in the 60-1000 Pa range) between sediments, with coarser-grained and higher porosity sediments promoting fracture at lower strengths. Fracture propagation greatly enhanced the connectivity and diminished the tortuosity of the void networks, thereby augmenting the continuous gas release flux.
\end{abstract}

\section{INTRODUCTION}

In situ gas generation and retention have significant environmental implications for numerous natural and industrial waste sediments. Methanogenesis within natural water systems such as shallow marine sediments, lakes, and dredging sludge ${ }^{1}$ represents a considerable, but poorly quantified, contribution to the global carbon budget and thus represents a significant source of uncertainty for climate change models. Conversely, carbon dioxide sequestration into deep $(>800 \mathrm{~m})$ sedimentary basins has been suggested as an option for balancing this budget. $^{2}$ A lesser known example of trapped sedimentary gases is encountered within historic nuclear waste sludge. ${ }^{3}$ Corrosion of metallic uranium fuel and nuclear cladding materials, supplemented by the radiolytic breakdown of water by soluble fission products (primarily $\mathrm{Cs}^{137}$ and $\mathrm{Sr}^{90}$ ), generates flammable hydrogen. Protecting the environment from various radioactinides inherent to these wastes within nuclear storage ponds, tanks, and silos requires that potential acute hydrogen releases are understood and effectively managed to prevent a breach of containment.
In natural sediments, an ebullient flux of methane is promoted by elevated winds, ${ }^{4}$ tides, and atmospheric pressure fluctuations, ${ }^{5}$ which effectively reduce the critical diameter necessary for a bubble to achieve buoyancy. ${ }^{6}$ However, under quiescent conditions, both theoretical models ${ }^{6}$ and $\mathrm{X}$-ray computed tomography (CT) imaging ${ }^{3}$ have shown the critical bubble diameters required for bubble ebullition to be prohibitively large, even under low yield strength conditions of $<10 \mathrm{~Pa}$. Instead, a recent study by the current authors ${ }^{7}$ proposed that gas migration and release from quiescent sediments are better explained by transport through connected networks of partially coalesced bubbles and cracks. Furthermore, this mechanism of enhanced gas transport is greatly augmented in the case of sediments prone to fracture during in situ bubble growth.

Received: May 21, 2019

Revised: $\quad$ September 23, 2019

Accepted: September 30, 2019

Published: September 30, 2019 
Comparison of sandy, silty, and clay-like sediments has shown that significant disparities in particle and pore size distributions greatly influence the capacity for gas retention, bubble size distribution, bubble morphology, and the retained gas profile with depth. ${ }^{8}$ While significant modeling studies have used linear elastic fracture mechanics (LEFM) to mathematically describe the growth and propagation of fractures, ${ }^{9-11}$ such models do not account for pore-scale sediment structures, which can influence whether the sediment supports fractures, spherical or dendritic bubbles. Little is known of how subtle differences in microstructure (the size, shape, and orientation of particles and pore networks ${ }^{12}$ ) between predominantly finegrained sediments can influence the gas retention behavior, including the tendency to fracture and the establishment of avenues for gas release. In this study, gas generation is investigated within three chemically similar, fine-grained $\mathrm{Mg}(\mathrm{OH})_{2}$-rich sediments, complemented by X-ray CT imaging of the retained bubble populations at a steady-state gas holdup. A two-phase Monte Carlo (MC) gas transport model is also presented to analyze the significance of the range, connectivity, and geometry of networks of coalesced bubbles in determining the gas release dynamics.

\section{MATERIALS AND METHODS}

Three $\mathrm{Mg}(\mathrm{OH})_{2}$-rich test materials are used throughout this study as nonactive analogues for the Magnox legacy waste found at Sellafield and various Magnox reactor sites across the U.K. The first is a commercial $\mathrm{Mg}(\mathrm{OH})_{2}$ powder called Versamag $^{13}$ (Martin Marietta Specialities), synthesized by the calcination, hydration, and precipitation of dolomitic lime; water is added for a prescribed solid concentration before thorough agitation with an overhead stirrer. For brevity, this test material is referred to as magnesium hydroxide powder sludge (MHPS). Two alternative test materials, corroded magnesium sludge (CMgS) and corroded Magnox sludge (CMS), are each manufactured by the UK's National Nuclear Laboratory by corroding raspings of magnesium metal and Magnox alloy, respectively, in heated water baths doped with sodium chloride. The solid concentrations of CMS and CMgS samples are determined from the loss in mass following $24 \mathrm{~h}$ drying at $80{ }^{\circ} \mathrm{C}$. Characterization of the particle size distributions, elemental and crystalline compositions, and shear deformation and dynamic mechanical behavior are included in the Supporting Information (SI).

2.1. Sediment Microstructure Characterization. The sediment microstructure was characterized using a combination of cryogenic-focused ion beam/scanning electron microscopy (cryo-FIB/SEM) and low-field nuclear magnetic resonance (LFNMR) analysis of the pore dimensions. Prior to imaging, samples were rapidly frozen by quenching with slush nitrogen before the temperature was increased and maintained at $-90{ }^{\circ} \mathrm{C}$ (under vacuum) for $8 \mathrm{~min}$ to sublime away the majority of the pore water. This approach has shown positive results in preserving the microstructure of soils ${ }^{14,15}$ and gels ${ }^{16}$ for imaging, demonstrating an excellent agreement with mercury intrusion porosimetry (MIP) ${ }^{15}$ and $\mathrm{NMR}^{16}$ data, respectively. A Helios G4 CX DualBeam microscope (FEI) was used to capture images of (1) the topography of a fractured surface of frozen sediment and (2) the interior wall of a borehole etched from the sample by the FIB or FIB cross section.

LFNMR is a powerful tool for investigating the internal structures of aqueous sediments, ${ }^{8,17}$ profiting from the proportionality between the rate at which the protons comprising the pore water lose their magnetic spin, or transverse relaxation time, $T_{2}$, and the pore body radii, $r_{\mathrm{pb}} \cdot{ }^{18,19}$ Analysis was conducted in accordance with the method outlined in Johnson et al., ${ }^{7}$ using mercury intrusion porosimetry (MIP) data for dried samples and LFNMR data for dried and rewetted samples to calibrate a corrected transverse relation strength, $\rho_{2}^{*}$, enabling the relaxation times to be translated to more relevant length dimensions, $r_{\text {th }}=\rho_{2}^{*}$ $T_{2}{ }^{7,20}$ where $r_{\text {th }}$ is the pore throat radius. MIP and LFNMR tests were undertaken using a $413 \mathrm{MPa}$ Autopore IV porosimeter (Micromeritics) and a MARAN Ultra benchtop NMR analyzer (Oxford Instruments, U.K.), respectively.

2.2. X-ray CT Imaging of in Situ Bubble Populations. Bubbles were generated within the sediment by introducing 4.4 $\mathrm{mL}$ of a $35 \% \mathrm{w} / \mathrm{w}$ hydrogen peroxide solution (Merck Chemicals, Germany), per liter of sediment, which decomposes to a volume of oxygen equivalent to $60 \%$ of the initial bed volume over the course of around $8 \mathrm{~h}^{7}$ The hydrogen peroxide solution was thoroughly distributed throughout the sediment at the start of each test by $60 \mathrm{~s}$ of homogenization with an impeller controlled by an overhead stirrer. Tests were performed at $0.35,1$, or $6.5 \mathrm{~L}$ scales, with the smallest scale tests imaged by X-ray CT. The $1 \mathrm{~L}$ tests were performed within $118 \mathrm{~mm}$ diameter cylinders, while the 0.35 and $6.5 \mathrm{~L}$ tests were performed within $150 \mathrm{~mm}$ long sideway mounted cylinders of 81 and $300 \mathrm{~mm}$ diameters, respectively (designed for axisymmetric X-ray attenuation within clinical CT scanners ${ }^{7}$ ). Gas holdup, or void fraction, was determined, for a broad range of sediment conditions $(30<\tau<1112 \mathrm{~Pa}, 1270<\rho<$ $1700 \mathrm{~kg} \mathrm{~m}^{-3}$ ) above the liquid limit, ${ }^{21}$ by monitoring volumetric bed swell $\left(\nu=1-V_{\text {in }} / V_{\max }\right.$, where $V_{\text {in }}$ and $V_{\max }$ are the initial and maximum bed volumes, respectively). ${ }^{3}$

Sedimentary bubbles are frequently generated experimentally by in situ chemical ${ }^{7}$ or biological ${ }^{5}$ reaction, high-pressure injection through a nozzle ${ }^{22}$ or depressurization. ${ }^{23,24}$ In situ reaction was deemed preferable as (1) it ensures that gas generation is global throughout the bed, (2) bubble growth occurs on a realistic time scale of several hours, and (3) bubble nucleation and growth commence at the pore scale, which is critical to investigating the role of microstructure on bubble growth. Hydrogen peroxide decomposition has been shown to provide repeatable kinetics independent of the $\mathrm{Mg}(\mathrm{OH})_{2}$ solid concentration or yield strength conditions. ${ }^{3}$

Previous work by the current authors ${ }^{3}$ has shown that this method of in situ gas generation results in steady-state gas holdup, bubble populations, and bubble dimensions within the first $6 \mathrm{~h}$ of gas generation and thus the bubbles can be considered mature $^{25}$ after $6 \mathrm{~h}$. Under these steady-state gas holdup conditions, the retained bubble populations within four $350 \mathrm{~mL}$-scale sediment tests were visualized using highresolution X-ray $\mathrm{CT}$, including each of the test sediments at $\approx 30 \mathrm{~Pa}$ yield strength and an additional higher strength sample of $\approx 130$ PA CMS. The MHPS and CMgS sediments were imaged using an Inveon dual positron emission tomography (PET)/CT scanner (Siemens, Germany) in accordance with the method outlined in Johnson et al. ${ }^{7}$ A similar XTremeCT (Scanco Medical, Switzerland) scanner was used to investigate the CMS test material. Both scanners use cone-beam X-ray sources, capturing 180 projections at a $1^{\circ}$ interval, achieving voxel resolutions in the order of $50 \mu \mathrm{m}$ after reconstruction. The imaging protocols are further summarized in Table S1. 
A combination of FIJI ImageJ, ${ }^{26}$ DigiUtility (Structure Vision Ltd., U.K.), ${ }^{27}$ and Matlab v. R2017a (Mathworks) was used to diminish image artifacts, threshold, and extract quantitative bubble size information during postprocessing. Bubble size analysis for interconnected bubble populations was achieved by measuring three perpendicular chord lengths at 1 $\times 10^{8}$ random sites within the void network and applying an ellipsoidal chord-length-to-diameter transformation algorithm $^{7,28}$ in Matlab.

2.3. Monte Carlo Modeling of Gas Migration. Extensive networking between partially coalesced bubbles enables gas transport to be investigated on time scales of seconds, in contrast to the much slower process of aqueous diffusion through pore water. ${ }^{7}$ A Monte Carlo model (MCM) originally used to study aggregation and sedimentation dynamics, ${ }^{29}$ and later gas diffusion, was further adapted to simulate gas migration through sediments with complex void geometries. Such complex void geometries could include sediments containing discrete, nonebullient (static) bubble networks, for which long-range gas transport through the sediment is not possible without (1) mass exchange at the bubble-pore water interface and (2) transport of volatiles in the aqueous phase. This is particularly relevant to immature or low-voidage bubble populations where long-range networks have not had time to form, or within sediments where bubble armoring inhibits partial bubble coalescence. ${ }^{30} \mathrm{~A}$ detailed description of the principles underlying the MCM is included in the SI; however, in brief, the adapted model mimics Fick's second law of diffusion within the aqueous (pore water) and gaseous (void) phases through random motion between neighboring voxels in the reconstructed CT images, while Henry's law is used to dictate the rate of mass exchange between the voidage and ambient pore water. The relevant diffusion coefficients ${ }^{31,32}$ and dimensionless Henry's law coefficient ${ }^{33}$ employed by the model are detailed in Table 1 .

Table 1. Parameters Used in the MCM To Determine Composite Hydrogen Diffusion Through Voids and Pore Water

$\begin{array}{ccc}D_{\mathrm{H}_{2}, \mathrm{H}_{2}}\left(\mathrm{~m}^{2} \mathrm{~s}^{-1}\right) & D_{\mathrm{H}_{2}, \mathrm{H}_{2} \mathrm{O}}\left(\mathrm{m}^{2} \mathrm{~s}^{-1}\right) & K_{\mathrm{H}, \mathrm{cc}} \\ 1.604 \times 10^{-4} & 4.50 \times 10^{-9} & 1.96 \times 10^{-2}\end{array}$

This approach for simulating gas migration benefits from very simple front-end implementation in comparison to continuum-based flow modeling. The model can be implemented directly using real tomographic datasets of complex void geometries without the need for meshing. In this study, the calculations were performed using $600^{3}$ voxel $\mathrm{CT}$ reconstructions of $\approx 30 \mathrm{~Pa}$ yield strength samples of the three test materials and a higher strength $132 \mathrm{~Pa}$ CMS sample, each after $6 \mathrm{~h}$ in situ gas generation. The primary disadvantage is that the simulations themselves can be time consuming to undertake. Four tomography datasets were simulated using individual $3 \mathrm{GHz}$ CPU Intel i5 processors with $2 \times 8 \mathrm{~Gb}$ RAM due to issues with conserving mass when running the simulation across multiple cores. Consequently, $1 \mathrm{~min}$ of real diffusion required around 4 weeks of simulation time.

\section{RESULTS AND DISCUSSION}

3.1. Sediment Microstructure Characterization. Light scattering analysis (Figure S2) revealed each of the test materials to be largely fine-grained with modal particle diameters in the order of 3-4 $\mu \mathrm{m}$. The PSDs indicate largely silt-like $\left(2<d_{\mathrm{p}}<63 \mu \mathrm{m}\right)$ sediments with up to $21 \%$ clay-sized $(<2 \mu \mathrm{m})$ fractions. The principal differences in PSD lie in the fact that MHPS exhibits few sand-sized particles $(0.2 \%>63$ $\mu \mathrm{m})$, while the CMS and CMgS are richer in coarse silt and medium sand-sized grains, respectively.

Energy-dispersive X-ray spectroscopy (EDX) and X-ray powder diffraction (XRD) analysis (Figure S3) revealed very similar compositions. Each of the test materials was found to contain almost exclusively brucite $\left(\mathrm{Mg}(\mathrm{OH})_{2}\right)$ with only trace amounts $(<1 \%)$ of aluminum, silicon, and calcium. For the $\mathrm{CMgS}$, these elements were attributed to traces of crushed slate contaminants, while the aluminum within the CMS derives from the $0.8 \% \mathrm{Al}$ content present in the Magnox alloy from which it was synthesized.

In spite of the apparent compositional similarity, cryo-FIB/ SEM imaging (Figure $1 \mathrm{a}-\mathrm{c}$ ) revealed a distinct structure in the case of the CMS, with high aspect ratio acicular, or needle-like, crystals resembling the carbonated brucite seen in Maher et al., ${ }^{34}$ contrasting the more common hexagonal platelet brucite structure $^{35}$ of the MHPS and CMgS. The nuclear waste sediments exhibit an open structure, with high void ratio, which is analogous to a range of natural sediments, including clay-dominated sediments at very shallow depths, ${ }^{12}$ calcareous sediments, ${ }^{36}$ and organo-mineral agglomerations (mixtures of particles formed by organisms such as fecal pellets and mineral grains) that form in areas with rapid sedimentation that induces significant organic matter decomposition. ${ }^{37}$ In particular, acicular crystals observed in the CMS sediment are highly analogous to calcareous sediments dominated by aragonite needles. ${ }^{36}$

This distinctive CMS crystal morphology has some significant implications for the sediment microstructure and shear deformation behavior. The high aspect ratio crystals enable the CMS to form a continuous solid skeleton, or gel, at reduced solid concentrations $\left(\omega<0.2 \mathrm{~kg} \mathrm{~kg}^{-1}\right.$; see Figure S4b). Correspondingly, the CMS has a significantly greater porosity and water content than the CMgS or MHPS at an equivalent yield strength. In the instance of $30 \mathrm{~Pa}$ yield strength sediments, the CMS will be around $18 \%$ higher in porosity and $11 \%$ lower in bulk density than the CMgS and MHPS. However, weak intergranular contacts between needlelike crystals give the CMS skeleton a reduced stiffness at low strains (see Figure $S 4 c, d$ ). CMS of $\approx 30$ Pa yield strength has a storage modulus, $G^{\prime}$, in the order of $10^{4} \mathrm{~Pa}$, around an order of magnitude lower than the MHPS and CMgS.

Figure $1 \mathrm{~d}$ presents the pore throat size distributions for three CMS samples of different yield strengths; $84-91 \%$ of the total detected pore volumes for each sample are connected by pore throats in the $0.1<r_{\text {th }}<0.6 \mu \mathrm{m}$ range, around an order of magnitude smaller than the modal particle sizes demonstrated in Figure S2. The remaining pore volume is almost entirely accounted for by a small number of large $\approx 2 \mu \mathrm{m}$ scale pores. Given that $\approx 99 \%$ of the porosity is connected by throats of at least $100 \mathrm{~nm},{ }^{38}$ these soft sediments can safely be characterized as macroporous, punctuated by a small number of micron-scale fracture sites, ${ }^{39}$ or cleats.

In addition to enhancing the sediment bulk yield strength, increasing the solid concentration (usually achieved by dewatering the sediment under compression) also causes the majority of pore throats to constrict. This contraction is consistent with observations from discrete element modeling 


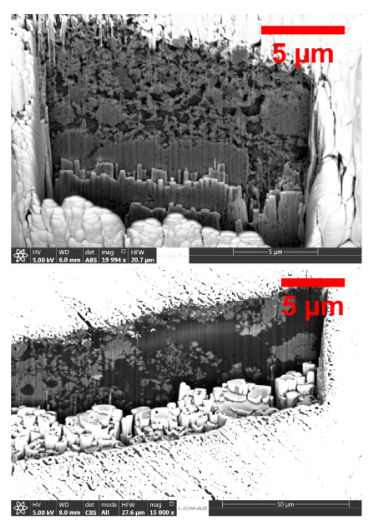

(a)

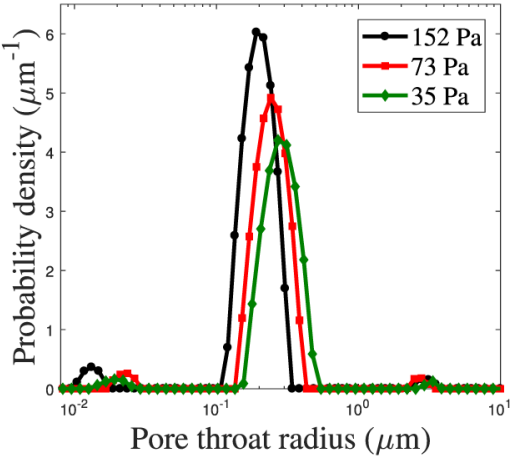

(d)

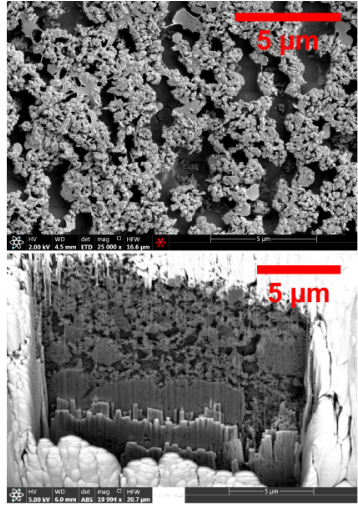

(b)

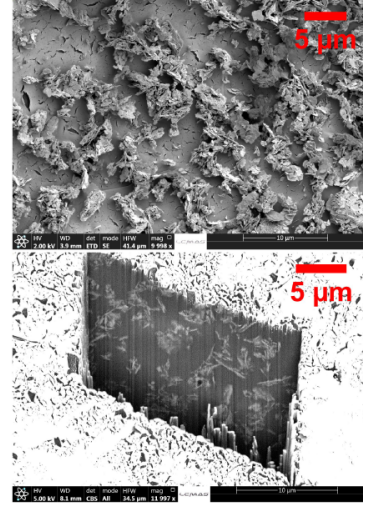

(c)

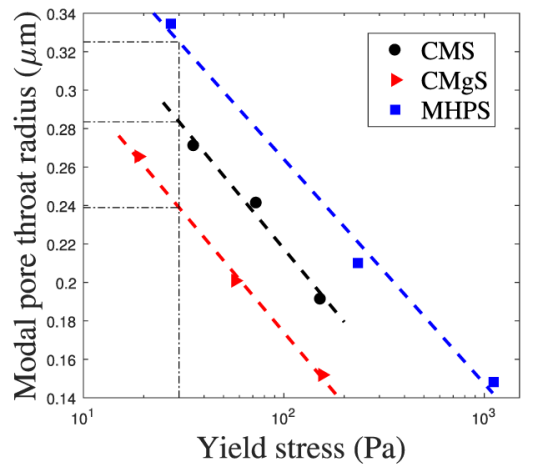

(e)

Figure 1. Cryo-SEM images showing the fractured topography and focused ion beam etched cross sections of (a) $\omega \approx 0.4 ; \tau \approx 70$ Pa MHPS, (b) $\omega$ $\approx 0.42 ; \tau \approx 148 \mathrm{CMgS}$, and (c) $\omega \approx 0.27 ; \tau \approx 86 \mathrm{~Pa}$ CMS sediments, along with LFNMR analysis of (d) pore throat size distributions for CMS and (e) modal pore throat radii as a function of yield strength for the various $\mathrm{Mg}(\mathrm{OH})_{2}$-rich legacy waste test materials (dashed lines represent semilog regression fits for each test material).

for coarser, noncohesive sandy sediments in Mahmoodlu et al. $^{40}$ Pore throat constriction increases the resistance to a nonwetting fluid (such as hydrogen bubbles) intruding into adjacent pore space by capillary invasion ${ }^{41}$ and is further demonstrated by Figure 1e, which presents modal pore throat radii as a function of shear yield strength for the three test materials. Curiously, the hierarchy of pore throat radii (MHPS $>\mathrm{CMS}>\mathrm{CMgS}$ ) finds the CMS to have intermediate-sized pore throats, despite its apparently distinct particle morphology and elevated porosity at comparable yield strength. However, the pore dimensions likely represent a complex product of particle size distribution, crystal morphology, porosity, and the strength of interparticle interactions and are thus far from trivial to predict. Logically, if the CMS has a significantly larger total porosity and more constricted pore throats than the MHPS, a larger pore-body-to-throat ratio would be anticipated. However, the pore-body-to-throat ratio is not easily characterized without first drying the sediment, ${ }^{20}$ and the microstructure is unlikely to be preserved during the drying process.

The disparity in pore throat scales demonstrated between the three test materials is potentially significant to the mechanism of in situ bubble growth. Returning to the example of $30 \mathrm{~Pa}$ yield strength sediments, the $\mathrm{CMgS}$ would experience $35 \%$ greater capillary entry pressures (given the YoungLaplace relationship, ${ }^{42} \Delta \mathrm{P}_{\mathrm{i}}=P_{\mathrm{b}}-P_{\mathrm{w}} \propto r_{\text {th }}^{-1}$, where $P_{\mathrm{b}}$ and $P_{\mathrm{w}}$ are the internal bubble and pore water pressures, respectively) between the majority of its pores than the MHPS or CMS.
However, the narrow modal pore throat dimensions of less than $340 \mathrm{~nm}$ observed for these fine-grained test materials is likely to preclude gas invasion into adjacent pore space due to prohibitively high capillary entry pressures. ${ }^{1,25,43}$ Instead, it is anticipated that bubble growth will be limited to the cavity expansion and fracture propagation growth mechanisms, both of which involve deformation of the surrounding sediment skeleton.

3.2. Gas Retention Behavior. The maximum void fractions, or gas holdup, were observed during $8 \mathrm{~h}$ in situ gas generation within sediments at 1 and $6.5 \mathrm{~L}$ scales, as detailed in Section 2.2, and are presented across a range of shear yield strength conditions in Figure 2. The six $6.5 \mathrm{~L}$-scale experiments represented by open symbols in Figure 2 were deemed to demonstrate acceptable agreement with the literscale data. The disparity in gas holdup between the test materials appears significant, although a number of consistent themes emerge. Each of the test materials exhibits a large holdup regime at low yield strengths, with void fractions in the order of $0.27-0.40$. Above a critical yield strength, or narrow range of yield strengths, gas holdup diminishes to maximum void fractions in the order of 0.15 . For the CMS, this transition occurs above yield strengths of around $60 \mathrm{~Pa}$. A similar trend occurs for the $\mathrm{CMgS}$ above $120 \mathrm{~Pa}$ and above around a 1000 Pa yield strength for the MHPS (see the dashed vertical lines in Figure 2). Unfortunately, it was not possible to adequately distribute hydrogen peroxide through greater than $\mathrm{kPa}$ strength 


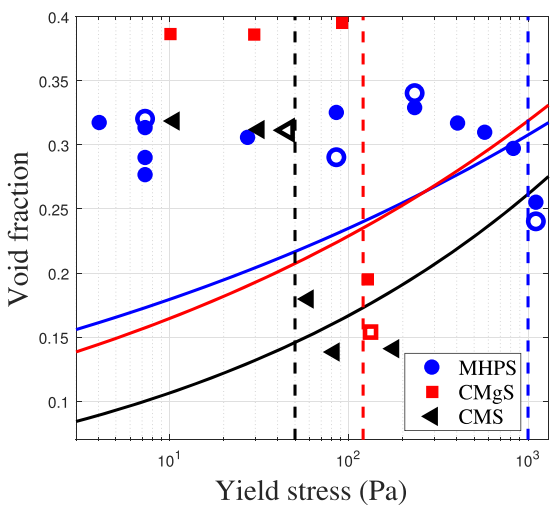

Figure 2. Maximum void fractions observed across a range of yield strength conditions for three $\mathrm{Mg}(\mathrm{OH})_{2}$-rich sediments (many of the MHPS data are reproduced from Johnson et al. ${ }^{3}$ ); solid and open symbols represent 1 and $6.5 \mathrm{~L}$-scale tests, respectively; the solid line profiles represent the neutral buoyancy condition, whereby the sediment density reaches equilibrium with an aqueous supernatant, and vertical dashed lines at $\tau=60,120$, and $1000 \mathrm{~Pa}$ indicate apparent transitions to a lower holdup regime above proposed critical fracture strengths.

MHPS to observe a similar $\approx 0.15$ void fraction plateau to the CMS.

The X-ray tomography studies of MHPS in Johnson et al., clearly indicate that the reduction in bed swell at $\approx 1 \mathrm{kPa}$ yield strength corresponded to the onset of fracture in that material. Furthermore, in van Kessel and van Kesteren, ${ }^{1}$ crack initiation within dredging sludge experiencing in situ methanogenesis was similarly observed to diminish the capacity for bed expansion. Thus, a critical fracture strength, $\tau_{\mathrm{f}}$, may demarcate a low-strength regime of near-spherical bubble growth by elastic/plastic cavity expansion from a regime of growth dictated by tensile fracture. The characteristics of the bubble population in the low-strength cavity expansion regime and the evidence for a microstructure-dependent critical fracture strength are discussed in Sections 3.3 and 3.4, respectively.

3.3. Gas Retention in the Cavity Expansion Regime. Figure $3 a-c$ reveals the bubble populations within the three test materials at similar yield strengths of $31 \pm 1 \mathrm{~Pa}$, each below the respective critical fracture strengths. Each lowstrength test material supports bubbles with a spherical geometry, 3-4 orders of magnitude greater than the LFNMR measured pore dimensions, indicating bubble growth by elastic/plastic cavity expansion. However, it is immediately apparent that the bubble dimensions are vastly dissimilar between the three sediments, reflected by the bubble size distributions (BSDs) presented in Figure $3 \mathrm{e}$ and the bubble characteristics summarized in Table 2. Two indicators suggest

Table 2. Characteristics of Bubble Populations in the Cavity Expansion Regime (As Determined by X-ray Image Analysis), Including Void Fraction, $\nu$, Mean Bubble Diameter, $\bar{d}_{\mathrm{b}}$, 90th Percentile of the BSD, $d_{\mathrm{b}, 90}$, Specific Surface Area, SSA, Bubble Number density, $n_{\mathrm{b}}$, and the Contribution of the Largest Bubble Network to the Total Voidage, $\nu_{i, \max }$

\begin{tabular}{lcccccrr} 
sediment & $\begin{array}{c}\tau \\
(\mathrm{Pa})\end{array}$ & $\nu$ & $\begin{array}{c}\bar{d}_{\mathrm{b}} \\
(\mathrm{mm})\end{array}$ & $\begin{array}{c}d_{\mathrm{b}, 90} \\
(\mathrm{~mm})\end{array}$ & $\begin{array}{c}\text { SSA } \\
\left(\mathrm{mm}^{-1}\right)\end{array}$ & $\begin{array}{c}n_{\mathrm{b}} \\
\left(\mathrm{cm}^{-3}\right)\end{array}$ & $\nu_{\mathrm{i}, \max }$ \\
MHPS & 30 & 0.282 & 0.64 & 1.11 & 18.2 & 2913 & 0.995 \\
CMgS & 30 & 0.385 & 2.56 & 3.75 & 3.7 & 72 & 0.028 \\
CMS & 32 & 0.254 & 1.84 & 2.80 & 7.5 & 151 & 0.827 \\
\hline
\end{tabular}

that the tomographic resolution of $\approx 50 \mu \mathrm{m}$ is sufficient to capture the entire bubble populations. First, the Gaussian distributions of each of the BSDs decay to zero at bubble diameters greater than $80 \mu \mathrm{m}$. Second, the visible void fractions determined from image analysis, summarized in Table

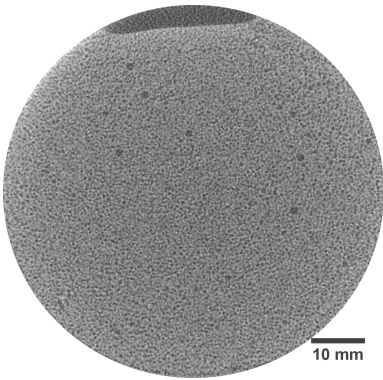

(a)

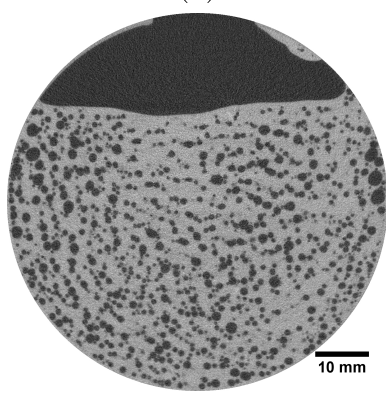

(c)

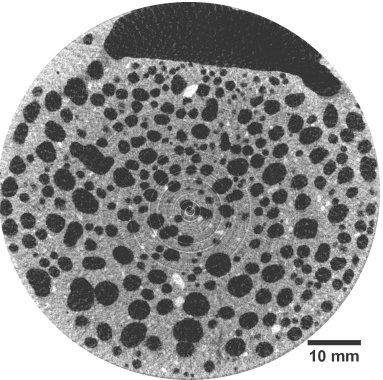

(b)

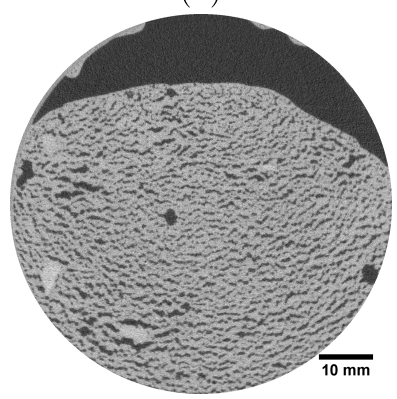

(d)

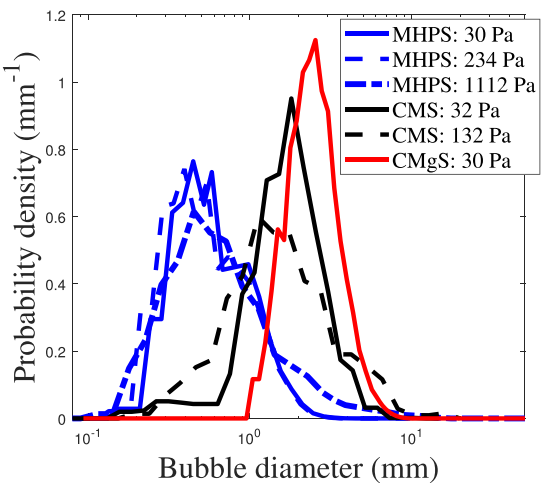

(e)

Figure 3. X-ray computed tomography slices through (a) $30 \mathrm{~Pa}$ MHPS, (b) $30 \mathrm{~Pa}$ CMgS, (c) $32 \mathrm{~Pa}$ CMS, and (d) $132 \mathrm{~Pa}$ CMS following a 6 h in situ hydrogen peroxide decomposition (following the cessation of bed expansion), together with (e) bubble size distributions within the three test materials. 


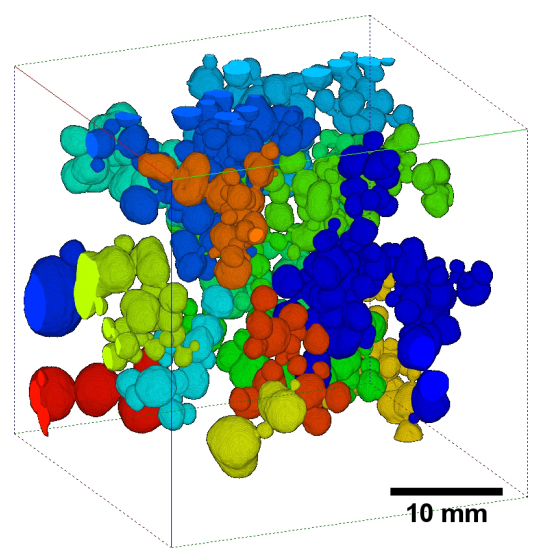

(a)

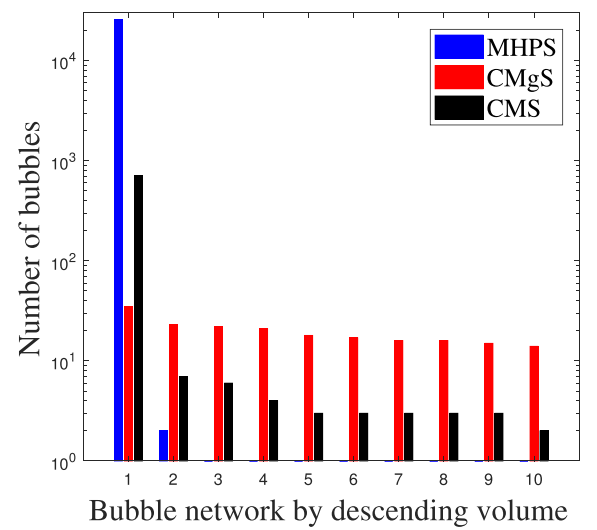

(b)

Figure 4. (a) CT reconstruction of the 16 largest bubble networks within $30 \mathrm{~Pa} \mathrm{CMgS}$, assigned different colors for visualization (with warmer colors representing reduced network volumes) and (b) comparison of the number of bubbles comprising the 10 largest bubble networks (sorted by descending bubble volume) for the three $\mathrm{Mg}(\mathrm{OH})_{2}$-rich test materials.

2, demonstrate good agreement with the apparent increase in bed volume over the duration of these small-scale CT experiments and the void fractions from the liter-scale tests summarized in Figure 2.

The smallest bubbles retained by the $\mathrm{CMgS}$ are a millimeter in diameter, much larger than those within the MHPS, for which $86 \%$ of bubbles are smaller than a millimeter. The lowstrength CMS retains intermediate-sized bubbles, with $22 \%$ of its population less than a millimeter in diameter and $10 \%$ of bubbles larger than $2.8 \mathrm{~mm}$. In fact, the disparity in BSD between the three test materials far outweighs the variation with yield strength for a particular test material, indicating that sediment microstructure has a greater influence on the BSD than yield strength.

The hierarchy in bubble size (CMgS > CMS > MHPS) coincides with the inverse hierarchy in bubble connectivity, with coarser bubble populations manifesting in diminished connectivity. The bubble connectivity is perhaps better demonstrated by Figure 4a, which shows the 16 largest networks of partially coalesced bubbles within the low-strength $\mathrm{CMgS}$. The largest of these networks contributes only $2.8 \%$ of the total holdup, contains just 52 partially coalesced bubbles, and does not traverse the width of the $32 \mathrm{~mm}$ wide field of view to provide a continuous pathway for gas migration through the sediment. Conversely, $99.5 \%$ of bubbles within the low-strength MHPS are interconnected within the same bubble network, composed of more than 20000 bubbles. The disparity in bubble connectivity is illustrated by Figure $4 \mathrm{~b}$, which presents the number of bubbles, $N_{\mathrm{i}}$, comprising the 10 largest bubble networks in each sediment, estimated from the network volumes, $V_{\mathrm{i}}$, and the bubble number densities, $n_{\mathrm{b}}$, derived from the BSD probability densities, $p\left(d_{\mathrm{b}}\right)$

$$
N_{\mathrm{i}}=V_{\mathrm{i}} n_{\mathrm{b}} n_{\mathrm{b}}^{-1}=\frac{\pi}{6} \int_{0}^{\infty}\left[p\left(d_{\mathrm{b}}\right) d_{\mathrm{b}}^{3}\right] d\left(d_{\mathrm{b}}\right)
$$

In one respect, the inverse correlation between bubble size and connectivity is intuitive as coalescence is a surface phenomenon, and a population composed of fewer, but coarser bubbles will present a much smaller specific surface area (SSA). However, the differences in bubble size and connectivity between the three sediments could equally be explained by their differences in the microstructure. Recalling Figure 1e, the hierarchy of pore throat dimensions indicated by LFNMR analysis (MHPS > CMS > CMgS) resembles that of bubble connectivity. Thus, the more constricted the sedimentary pore throats prior to the onset of gas generation, the less likely bubbles occupying adjacent pores are to interact and partially coalesce.

It has been established that the mature bubbles visible in Figure 3 are orders of magnitude larger than the sediment pore throat dimensions. At a very early stage of bubble growth, the bubble occupies the pore body and begins to deform the surrounding sediment matrix. ${ }^{41}$ Just as Figure 1e demonstrated constriction of the pore throats with increased consolidation, this period of cavity expansion is likely to induce the widening of the pore throats in unison with the pore body expansion, thereby diminishing the capillary invasion pressure. ${ }^{44}$ Eventually, the capillary invasion pressure may drop sufficiently to enable the bubble to intrude through the pore throat and either (1) occupy multiple adjacent pores or (2) approach another bubble occupying an adjacent cavity and coalesce.

Invasion into adjacent pore bodies would induce a drop in the internal bubble pressure ${ }^{42}$ and diminish the driving force for further bubble growth. Likewise, two partially coalesced bubbles will require a greater increase in internal pressure to induce further cavity expansion than the two discrete bubbles with elevated Laplace pressures. Thus, the sediment microstructure may dictate the termination condition for bubble growth by cavity expansion in some instances, rather than exhaustion of the diffusive supply due to (1) diminishing source strength or (2) elevated internal bubble pressures extinguishing the concentration gradient and inducing a nogrowth condition. ${ }^{11}$ For cavity expansion growth limited by either coalescence or capillary invasion, a sediment with narrow pore throats could undergo a prolonged period of cavity expansion before growth is terminated, resulting in a population of larger bubbles and reduced connectivity, consistent with the inverse correlation observed between BSD and pore throat radii.

Over longer time scales than these relatively short-duration laboratory-scale tests, a second phenomenon, which may contribute toward creating a smaller population of larger bubbles, or bubble coarsening, is Ostwald ripening. ${ }^{45,46}$ The inverse relationship between internal bubble pressure and bubble volume makes smaller bubbles more soluble, driving diffusive transfer from small bubbles toward proximate larger 
bubbles. Adjacent bubbles therefore grow competitively, with large bubbles growing at the expense of their smaller neighbors, generating a thermodynamically favorable reduction in total surface energy over time. ${ }^{47}$ This indicates how a poorly connected bubble population, such as that supported by the $\mathrm{CMgS}$ in Figure $3 \mathrm{~b}$, might have evolved over time. Conversely, when bubbles are partially coalesced in a network, or particles are agglomerated within a larger aggregate particle, Ostwald ripening manifests as a widening of the necks between adjacent bodies, ${ }^{48}$ indicating an alternative ripening regime for populations consistent with the low-strength MHPS in Figure 3a.

Physical properties of the sediment can also influence the rate at which the bubble population evolves due to Ostwald ripening. It is generally acknowledged that the process is ratelimited by diffusion. ${ }^{47,49}$ Sediment microstructures dictate the tortuosity of the diffusion pathways for volatiles in solution ${ }^{50}$ and could thereby impact the rate of bubble coarsening. Subtle differences in particle size distribution (PSD) can also impact the structure and effectiveness of monolayers, which armor bubbles and inhibit Ostwald ripening. ${ }^{46}$

3.4. Transition to a Fracturing Regime Above a Critical Fracture Strength. The sharp reduction in gas holdup, demonstrated for each test material above a characteristic, material-dependent yield strength in Figure 2, was observed at around $60 \mathrm{~Pa}$ in the case of CMS. Figure $3 \mathrm{c}, \mathrm{d}$ presents X-ray tomography revealing the retained bubble populations at 32 and $132 \mathrm{~Pa}$, respectively, either side of this transitional yield strength. The uniform spherical bubbles with aspect ratios close to unity at $32 \mathrm{~Pa}$ become laterally oriented high aspect ratio fractures at $132 \mathrm{~Pa}$, punctuated by large spherical bubbles, closely resembling the behavior of $\mathrm{kPa}$ strength MHPS. ${ }^{7}$ Thus, the reduction in gas holdup coincides with the onset of fracture propagation. Crack formation was similarly linked with a reduction in bed swell in Johnson et al. ${ }^{7}$ and van Kessel and van Kesteren; ${ }^{1}$ however, it is not clear why the critical fracture strength, at which this transition in bubble growth behavior occurs, varies so significantly between the three $\mathrm{Mg}(\mathrm{OH})_{2}$-rich test materials in this study.

To understand the existence of, and variation in, critical fracture strength, it is necessary to review the mechanisms for bubble growth. The resistance to uniform, spherical bubble growth, quantified by the excess internal bubble pressure required for cavity expansion, $\Delta P_{\mathrm{e}}$, scales with sediment yield strength and the ratio of shear modulus, $G$, to yield strength ${ }^{1,51}$

$$
\Delta P_{\mathrm{e}}=P_{\mathrm{b}}-\sigma=\frac{4}{3} \tau\left(1+\ln \left|\frac{G}{\tau}\right|\right)
$$

where $P_{\mathrm{b}}-\sigma$ is the difference between the internal bubble pressure and the mean ambient sediment stress normal to the bubble surface. ${ }^{25}$ For typical shear modulus to shear strength ratios in the 50-100 range, ${ }^{52}$ the expression approximates to $\Delta P_{\mathrm{e}} \approx(7.1 \pm 0.5) \tau$. Conversely, materials with high tensile strength, $\sigma_{\mathrm{y}}$ (approximately double the shear yield strength), are often more prone to fracture as they are less likely to deform plastically, thereby dissipating energy, at a crack tip than low-strength ductile materials. ${ }^{33}$ For natural cohesive sediments, fracture toughness appears to increase marginally with increased shear strength, $K_{1 \mathrm{c}}=k \tau$, with low multipliers reported as $k=0.13-0.21$ in Winterwerp and van Kesteren ${ }^{52}$ and $k \approx 0.09$ for Canadian clay-like silts in Johnson et al. ${ }^{54}$ The critical pressure for fracture, $\Delta P_{\mathrm{f}}$, is, in turn, proportional to the fracture toughness raised to the power of $6 / 5$ according to LEFM $^{9,55}$

$$
\Delta P_{\mathrm{f}}=P_{\mathrm{b}}-\sigma=\frac{K_{\mathrm{lc}}^{6 / 5} \pi^{3 / 5}\left(1-k_{\nu}^{2}\right)}{12^{1 / 5}\left(E V_{\mathrm{b}}\right)^{1 / 5}}
$$

where $k_{\nu}$ and $E$ are Poisson's ratio and Young's modulus, respectively, and $V_{\mathrm{b}}$ is the bubble volume. The $K_{\mathrm{lc}}^{6 / 5}$ and $E^{-1 / 5}$ dependences of the fracture pressure, combined with the very mild increase in fracture toughness with yield strength, indicate that fracture pressure increases much less rapidly with increased yield strength than the cavity expansion pressure. To illustrate this point, for a theoretical soft sediment with fracture toughness $K_{1 \mathrm{c}}=0.17 \tau \tau^{52}$ shear modulus $G=75 \tau^{52}$, Young's modulus $E=2 G\left(1+k_{\mathrm{v}}\right)$, and Poisson's ratio of $k_{\nu}=$ 0.45 , $^{56}$ the derivatives of the two critical pressures with respect to yield strength approximate as follows

$$
\begin{aligned}
& \frac{d \Delta P_{\mathrm{f}}}{d \tau} \approx 0.048 V_{\mathrm{b}}^{-1 / 5} \\
& \frac{d \Delta P_{\mathrm{e}}}{d \tau} \approx 7.1
\end{aligned}
$$

Hence, for any bubble greater than $300 \mu \mathrm{m}$ in equivalent spherical diameter, increasing the yield strength of this theoretical sediment will increase the cavity expansion pressure more than it will increase the fracture pressure. Bubble dimensions in the order of $300 \mu \mathrm{m}$ are around 3 orders of magnitude larger than the pore dimensions but relatively small in comparison with the mature bubble dimensions observed in Figure 3, potentially indicating an initial period of cavity expansion prior to fracture. Thus, for most realistic sediment conditions, consolidation, or increasing yield strength, will increase proclivity for fracture, giving credence to a critical strength at which fracture growth begins to dominate. One particular advantage of a critical yield strength is that fracture toughness characterization remains a relatively immature field for soft materials and can require fairly complex bespoke equipment for measurements in the field. ${ }^{54,55}$ Conversely, yield strength can be characterized remotely using slump tests, ${ }^{57}$ which, in a nuclear context, reduces exposure of workers to radiation.

The significant variation in critical fracture strength between the three $\mathrm{Mg}(\mathrm{OH})_{2}$-rich test sediments still requires explanation. The sediment microstructure will influence the propensity for fracture by (1) the provision of interstitial crack sites particularly vulnerable to fracture nucleation and (2) the influence of microstructure on bulk mechanical properties. Both effects are reflected by the LEFM model in eq 3, which demonstrates that the requisite fracture pressure will depend not only on the sediment's mechanical properties, such as fracture toughness and Young's modulus, but also on the bubble or initial crack dimensions, with a $V_{\mathrm{b}}^{-1 / 5}$ dependency. ${ }^{9,55}$ Fractures are therefore most likely to nucleate at, and propagate along the major axis of, large microstructural defects, ${ }^{58}$ such as the small number of micron-scale pores observed from the LFNMR analysis of the CMS (Figure 1d). The fact that the MHPS shows no evidence of these micronscale cleats ${ }^{7}$ may well contribute to the absence of fracturing at sub-kPa yield strengths.

However, fracturing is observed globally in Figure 3d rather than solely at the largest pores, indicating a disparity in the bulk mechanical and fracture resistance properties between the 


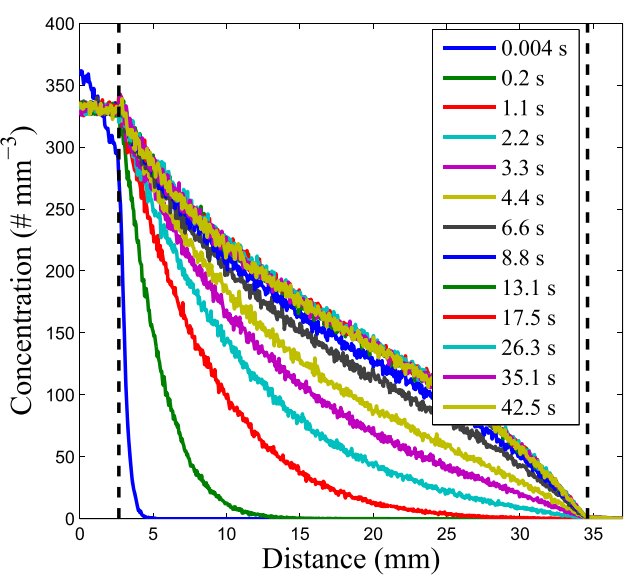

(a)

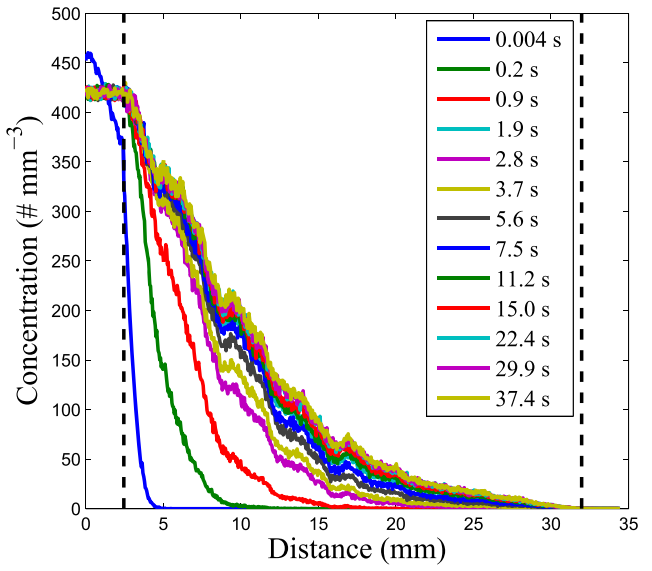

(c)

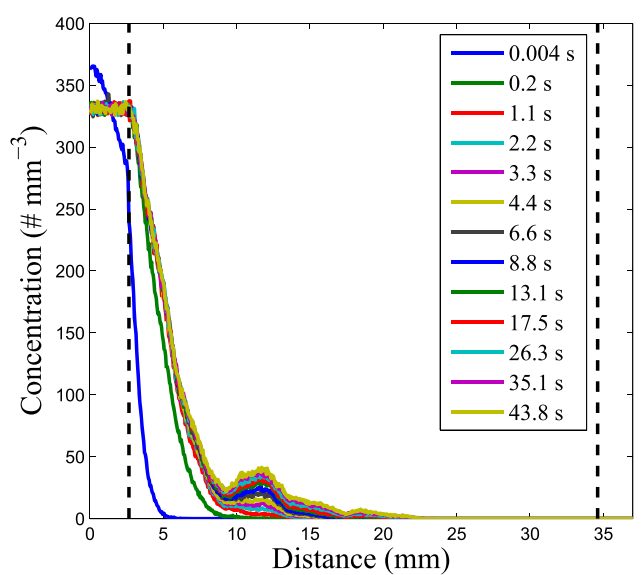

(b)

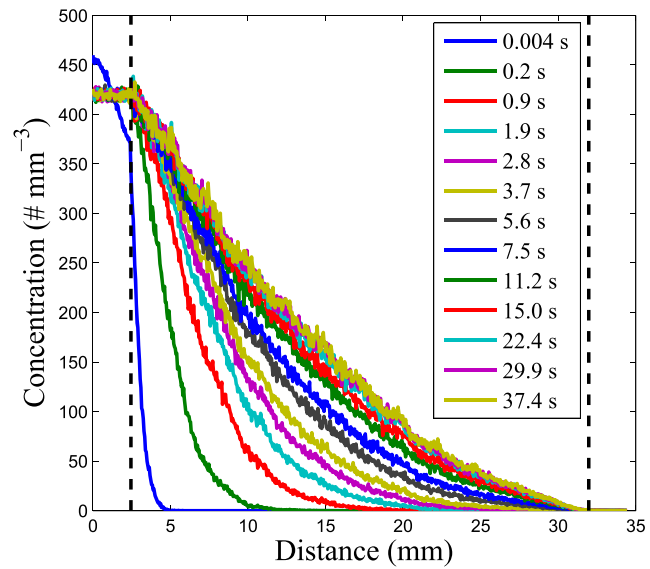

(d)

Figure 5. Evolving hydrogen concentration profiles during Monte Carlo diffusion simulations through (a) 30 Pa MHPS, (b) 30 Pa CMgS, (c) 32 $\mathrm{Pa}$ CMS, and (d) $132 \mathrm{~Pa}$ CMS.

test materials. Equation 3 identifies the particular significance of fracture toughness and, to a lesser extent, stiffness in determining the requisite fracture pressure. One principal difference between the test materials, revealed by vane rheology in Figure S4b, was that the CMS gels at lower solid concentrations or higher porosity. The, relatively limited, data on fracture toughness of soft sediments ${ }^{54,59}$ have shown exponential reductions in fracture toughness with increased porosity, $K_{1 \mathrm{c}}=a \exp (-b \phi)$, where $a>10^{4}$ and $7<b<16,{ }^{59}$ which may well contribute to its diminished critical fracture strength. Furthermore, an inverse, or inverse square, correlation exists between fracture toughness and average grain radius. ${ }^{43,54}$ An average grain size is not a particularly adequate representation of the complex bi- or trimodal PSDs for these $\mathrm{Mg}(\mathrm{OH})_{2}$-rich sediments; however, the particularly fine-grained MHPS $\left(d_{50}=4.4 \mu \mathrm{m}\right)$ demonstrates the greatest critical fracture toughness and the coarsest-grained CMS $\left(d_{50}=\right.$ $8.2 \mu \mathrm{m})$ the weakest.

The sediment stiffness also appears in LEFM models with an $E^{-1 / 5}$ dependence. Young's modulus is typically reported as the measure of sediment stiffness, where dynamic mechanical analysis of the linear viscoelastic region may be more appropriate for viscoelastic solids (see Figure S4c,d). Better measures of stiffness would be the norm $\left(\left|G^{*}\right|=\sqrt{{G^{\prime 2}}^{2}+G^{\prime 2}}\right)$ of the complex shear modulus $\left(G^{*}=G^{\prime}+i G^{\prime \prime}\right)$ or the storage modulus itself, which are practically equivalent for dominantly solid-like materials $\left(G^{\prime} / G^{\prime \prime} \geq 10\right)$. At yield strengths of $\approx 30$ $\mathrm{Pa}$, the storage modulus is a factor of 5-6 lower for CMS than those for the MHPS and CMgS. A reduction in stiffness actually implies an increase in fracture pressure according to LEFM, although the stiffness dependence is weak in comparison to the $K_{1 \mathrm{c}}^{6 / 5}$ dependence on fracture toughness and so the influence of the reduced porosity outweighs that of stiffness. Given the apparent significance of microstructure on fracture behavior, there would be tremendous advantages in extending grain-scale models of bulk mechanical properties ${ }^{43}$ to microstructures of more complex cohesive sediments with multimodal PSDs and alternative particle morphologies.

3.5. Influence of Bubble Geometry on Gas Transport Dynamics. X-ray CT has demonstrated highly varied bubble populations retained by sediments with subtly different microstructures and mechanical properties, from coarse spherical populations with low connectivity to sub-millimeter-scale populations with extensive connectivity, and vast networks of high aspect ratio fractures. It is equally important to understand how each bubble population facilitates gas transport through the bed and potentially limits the sediments' capacity for bed expansion. Understanding the mechanisms for gas migration is particularly significant for determining when the gas flux from the sediment approaches the rate of gas generation, preventing gas accumulation and terminating growth. To this end, the results of Monte Carlo gas diffusion calculations (detailed in Sections 2.3 and S2.3) for the three 
low-strength sediments in the cavity expansion regime $(\tau=31$ $\pm 1 \mathrm{~Pa})$ and CMS in the fracturing regime $(\tau=132 \mathrm{~Pa})$ are presented in Figure 5.

Figure $5 \mathrm{a}-\mathrm{c}$ demonstrates the rate of diffusion through the three low-strength $(\approx 30 \mathrm{~Pa})$ sediments within the cavity expansion growth regime. The rate of gas transport through the sediments reveals gas diffusivity in the hierarchy of MHPS $>\mathrm{CMS}>\mathrm{CMgS}$, predictably mirroring that of the bubble connectivity in Figure $4 \mathrm{~b}$ and Table 1 . Most notably, the $\mathrm{CMgS}$ demonstrates very poor gas transport dynamics. Since the bubbles supported by the $\mathrm{CMgS}$ do not form a continuous network traversing the width of the domain, interfacial mass exchange is required for a gas flux to pass through the sediment and into the sink region.

Henry's law dictates that the hydrogen concentration diminishes by a factor of 51 at each bubble-pore water interface, thereby greatly hindering gas migration across the domain. Furthermore, since only a very small percentage of bubble networks extend to the source region, only a fraction of the voidage is effectively utilized for gas transport at the prescribed boundary conditions, and so mass transport to the bulk of the void space is limited by the diffusivity of hydrogen in the pore water, which is around 4 orders of magnitude lower than in the gas phase. ${ }^{31,32}$ Thus, the short-range, poorly connected population of coarse millimeter-scale bubbles within the $\mathrm{CMgS}$ results in a negligible flux of gas from the bed. The negligible rate of chronic gas release, in turn, enables the substantial bed swell observed during the 1-6.5 L-scale tests to void fractions in the order of 0.40 .

Conversely, the $83-100 \%$ connectivity among the MHPS and CMS bubble populations, and the provision of a completely permeable gas pathway between source and sink regions, ensures a steady flux of gas from the bed controlled by the relatively rapid gas-phase diffusion. The high connectivity also ensures that the concentration profiles exhibit the Gaussian tail shape characteristic of Fick's second law of diffusion. ${ }^{60}$ The connectivity of the bubble networks and steady flux of gas from the bed limits further bed swell and imposes a ceiling in the gas holdup capacity at the $0.25-0.28$ void fractions observed in Figure 2.

Figure 5c,d contrasts the gas transport dynamics for CMS under cavity expansion $(32 \mathrm{~Pa})$ and fracturing $(132 \mathrm{~Pa})$ conditions, respectively. The fracturing sediment exhibits the faster gas transport dynamics, as indicated by the elevated tracer concentrations at the midpoint of the domain (roughly double those of the weaker sediment) once the equilibrium condition is attained after around $30 \mathrm{~s}$. This reflects the fact that fracturing increases the connectivity of the bubble population from 83 to $94 \%$ and greatly diminishes the tortuosity of the lateral diffusion path. Significantly, the fracturing sediment demonstrates this enhanced permeability at a reduced void fraction of 0.20 , compared with that of 0.25 for the lower strength, nonfracturing CMS (the void fractions within these CT sub-domains taken from $350 \mathrm{~mL}$-scale experiments can differ slightly from the liter and $6.5 \mathrm{~L}$-scale tests), explaining the cessation of bed expansion at reduced holdup conditions in the order of 0.15 in Figure 2.

The clear influence of sediment microstructure on the retained $\mathrm{BSD}$, the connectivity between bubbles, and the tendency for fracture therefore strongly dictate the gas release dynamics and capacity for gas holdup, with significant implications for both natural sediments and active nuclear waste sediments. First, the critical fracture strength defines a lower bound for yield strength at which LEFM models for fracture propagation apply. Second, it dictates yield strength conditions of diminished gas holdup and enhanced rates of continuous gas release. Thus, the critical yield strength provides a means of identifying natural sediments likely to contribute substantial methane releases or radioactive waste packages posing an increased risk of acute flammable gas releases and potential radioisotope release into the environment.

\section{ASSOCIATED CONTENT}

\section{S Supporting Information}

The Supporting Information is available free of charge on the ACS Publications website at DOI: 10.1021/acs.est.9b03034.

Characterization of the three test materials in terms of their chemical composition, particle size distribution, rheology, and dynamic mechanical behavior, X-ray tomographic imaging protocol and Monte Carlo diffusion model (PDF)

\section{AUTHOR INFORMATION}

\section{Corresponding Author}

*E-mail: T.N.Hunter@leeds.ac.uk. Phone: +44 (0)113 3432790.

ORCID

Michael Johnson: 0000-0003-2124-3717

David Harbottle: 0000-0002-0169-517X

Timothy N. Hunter: 0000-0003-3922-491X

Notes

The authors declare no competing financial interest.

\section{ACKNOWLEDGMENTS}

The authors wish to thank the Nuclear Decommissioning Authority (NDA), Sellafield Ltd., and the Engineering and Physical Sciences Research Council (EPSRC) for funding this work through an industrial case award (Grant EP/K504440) affiliated with the Decommissioning, Immobilisation and Storage Solutions for Nuclear Waste Inventories (DISTINCTIVE) consortium (Grant EP/L014041/1). The authors also thank Sellafield Ltd. for postdoctoral research funding and support. Further acknowledgment is given to Dr Nagitha Wijayathunga of the University of Leeds Institute of Medical and Biological Engineering, Karine Mardon at the University of Queensland's Center for Advanced Imaging, as well as Samuel Allshorn and Carlos Grattoni of the University of Leeds Wolfson Laboratory for their expertise and assistance with $\mathrm{X}$ ray $\mathrm{CT}$ and nuclear magnetic resonance data acquisition. The authors thank the reviewers for their valued contribution to this work.

\section{REFERENCES}

(1) van Kessel, T.; van Kesteren, W. G. M. Gas production and transport in artificial sludge depots. Waste Manage. 2002, 22, 19-28.

(2) Luhmann, A. J.; Kong, X. Z.; Tutolo, B. M.; Ding, K.; Saar, M. O.; Seyfried, W. E. Permeability reduction produced by grain reorganization and accumulation of exsolved $\mathrm{CO}_{2}$ during geologic carbon sequestration: A new $\mathrm{CO}_{2}$ trapping mechanism. Environ. Sci. Technol. 2013, 47, 242-251.

(3) Johnson, M.; Peakall, J.; Fairweather, M.; Biggs, S.; Harbottle, D.; Hunter, T. N. Yield stress dependency on the evolution of bubble populations generated in consolidated soft sediments. AIChE J. 2017, $63,3728-3742$. 
(4) Keller, M.; Stallard, R. F. Methane emission by bubbling from Gatun Lake, Panama. J. Geophys. Res.: Atmos. 1994, 99, 8307-8319. (5) Liu, L.; Kock, T. D.; Wilkinson, J.; Cnudde, V.; Xiao, S.; Buchmann, C.; Uteau, D.; Peth, S.; Lorke, A. Methane bubble growth and migration in aquatic sediments observed by micro-scale X-ray computed tomography. Environ. Sci. Technol. 2018, 52, 2007-2015.

(6) Wheeler, S. J. Movement of large gas bubbles in unsaturated fine-grained sediments. Mar. Geotechnol. 1990, 9, 113-129.

(7) Johnson, M.; Peakall, J.; Fairweather, M.; Biggs, S.; Jia, X.; Harbottle, D.; Hunter, T. N. Enhanced gas migration through permeable bubble networks within consolidated soft sediments. AIChE J. 2018, 4131-4147.

(8) Liu, L.; Wilkinson, J.; Koca, K.; Buchmann, C.; Lorke, A. The role of sediment structure in gas bubble storage and release. $J$. Geophys. Res.: Biogeosci. 2016, 121, 1992-2005.

(9) Johnson, B. D.; Boudreau, B. P.; Gardiner, B. S.; Maass, R. Mechanical response of sediments to bubble growth. Mar. Geol. 2002, 187, 347-363.

(10) Katsman, R. Correlation of shape and size of methane bubbles in fine-grained muddy aquatic sediments with sediment fracture toughness. J. Struct. Geol. 2015, 70, 56-64.

(11) Algar, C. K.; Boudreau, B. P. Stability of bubbles in a linear elastic medium: Implications for bubble growth in marine sediments. J. Geophys. Res.: Earth Surf. 2010, 115, No. F03012.

(12) Bennett, R. H.; Bryant, W. R.; Keller, G. H. Clay fabric of selected submarine sediments; fundamental properties and models. J. Sediment. Res. 1981, 51, 217-232.

(13) Johnson, M.; Peakall, J.; Fairweather, M.; Biggs, S. R.; Harbottle, D.; Hunter, T. N. Characterisation of multiple hindered settling regimes in aggregated mineral suspensions. Ind. Eng. Chem. Res. 2016, 55, 9983-9993.

(14) Campbell, R.; Porter, R. Low-temperature scanning electron microscopy of micro-organisms in soil. Soil Biol. Biochem. 1982, 14, 241-245.

(15) Griffiths, F. J.; Joshi, R. C. Discussion: Change in pore size distribution due to consolidation of clays. Géotechnique 1990, 40, 303-309.

(16) Van Duynhoven, J. P.; Broekmann, I.; Sein, A.; Van Kempen, G. M.; Goudappel, G. J. W.; Veeman, W. S. Microstructural investigation of monoglyceride-water coagel systems by NMR and CryoSEM. J. Colloid Interface Sci. 2005, 285, 703-710.

(17) Jaeger, F.; Bowe, S.; Van As, H.; Schaumann, G. E. Evaluation of $1 \mathrm{H}$ NMR relaxometry for the assessment of pore-size distribution in soil samples. Eur. J. Soil Sci. 2009, 60, 1052-1064.

(18) D’Orazio, F.; Tarczon, J. C.; Halperin, W. P.; Eguchi, K.; Mizusaki, T. Application of nuclear magnetic resonance pore structure analysis to porous silica glass. J. Appl. Phys. 1989, 65, 742-751.

(19) Yao, Y.; Liu, D. Comparison of low-field NMR and mercury intrusion porosimetry in characterizing pore size distributions of coals. Fuel 2012, 95, 152-158.

(20) Xiao, D.; Jiang, S.; Thul, D.; Huang, W.; Lu, Z.; Lu, S. Combining rate-controlled porosimetry and NMR to probe full-range pore throat structures and their evolution features in tight sands: A case study in the Songliao Basin, China. Mar. Pet. Geol. 2017, 83, $111-123$.

(21) Boukpeti, N.; White, D.; Randolph, M.; Low, H. Strength of fine-grained soils at the solid-fluid transition. Géotechnique 2012, 62, $213-226$.

(22) Sun, Z.; Santamarina, J. C. Grain-Displacive Gas Migration in Fine-Grained Sediments. J. Geophys. Res.: Solid Earth 2019, 124, 2274-2285.

(23) Mahabadi, N.; Zheng, X.; Yun, T. S.; van Paassen, L.; Jang, J. Gas bubble migration and trapping in porous media: pore-scale simulation. J. Geophys. Res.: Solid Earth 2018, 123, 1060-1071.

(24) Oppenheimer, J.; Rust, R.; Cashman, K.; Sandnes, B. Gas migration regimes and outgassing in particle-rich suspensions. Front. Phys. 2015, 3, 1-13.
(25) Sirhan, S. T.; Katsman, R.; Lazar, M. Methane bubble ascent within fine-grained cohesive aquatic sediments: dynamics and controlling factors. Environ. Sci. Technol. 2019, 53, 6320-6329.

(26) Schindelin, J.; Arganda-Carreras, I.; Frise, E.; Kaynig, V.; Longair, M.; Pietzsch, T.; Preibisch, S.; Rueden, C.; Saalfeld, S. Schmid, B.; Tinevez, J. Y. Fiji: an open-source platform for biologicalimage analysis. Nat. Methods 2012, 9, 676-682.

(27) Menon, M.; Yuan, Q.; Jia, X.; Dougill, A. J.; Hoon, S. R.; Thomas, A. D.; Williams, R. A. Assessment of physical and hydrological properties of biological soil crusts using X-ray microtomography and modeling. J. Hydrol. 2011, 397, 47-54.

(28) Li, M.; Wilkinson, D. Determination of non-spherical particle size distribution from chord length measurements. Part 1: Theoretical analysis. Chem. Eng. Sci. 2005, 60, 3251-3265.

(29) Jia, X.; Wedlock, D. J.; Williams, R. A. Simulation of simultaneous aggregation and sedimentation. Miner. Eng. 2000, 13, $1349-1360$

(30) Kam, S.; Rossen, W. Anomalous capillary pressure, stress, and stability of solids-coated bubbles. J. Colloid Interface Sci. 1999, 213, 329-339.

(31) Reichenbacher, W.; Müller, P.; Klemm, A. Z. Diffusion von HT, DT und $\mathrm{T}_{2}$ in $\mathrm{H}_{2}$ und $\mathrm{D}_{2}$ bei $24{ }^{\circ} \mathrm{C}$. Z. Naturforsch. A 1965, 20, $1529-1536$

(32) Ferrell, R. T.; Himmelblau, D. M. Diffusion coefficients of hydrogen and helium in water. AIChE J. 1967, 13, 702-708.

(33) Morris, D.; Yang, L.; Giraudeau, F.; Sun, X.; Steward, F. Henry's law constant for hydrogen in natural water and deuterium in heavy water. Phys. Chem. Chem. Phys. 2001, 3, 1043-1046.

(34) Maher, Z.; Ivanov, P.; O’Brien, L.; Sims, H.; Taylor, R. J.; Heath, S. L.; Livens, F. R.; Goddard, D.; Kellet, S.; Rand, P.; Bryan, N. D. Americium and plutonium association with magnesium hydroxide colloids in alkaline nuclear industry process environments. J. Nucl. Mater. 2016, 468, 84-96.

(35) Gregson, C. R.; Goddard, D. T.; Sarsfield, M. J.; Taylor, R. J. Combined electron microscopy and vibrational spectroscopy study of corroded Magnox sludge from a legacy spent nuclear fuel storage pond. J. Nucl. Mater. 2011, 412, 145-156.

(36) Bennett, R. H.; Fischer, K. M.; Lavoie, D. L.; Bryant, W. R.; Rezak, R. Porometry and fabric of marine clay and carbonate sediments: Determinants of permeability. Mar. Geol. 1989, 89, 127152.

(37) Reimers, C. E. Organic matter in anoxic sediments off Central Peru: Relations of porosity, microbial decomposition and deformation properties. Mar. Geol. 1982, 46, 175-197.

(38) Yao, Y.; Liu, D.; Che, Y.; Tang, D.; Tang, S.; Huang, W. Petrophysical characterization of coals by low-field nuclear magnetic resonance (NMR). Fuel 2010, 89, 1371-1380.

(39) Yao, Y. B.; Liu, D. M.; Cai, Y. D.; Li, J. Q. Advanced characterization of pores and fractures in coals by nuclear magnetic resonance and X-ray computed tomography. Sci. China Earth Sci. 2010, 53, 854-862.

(40) Mahmoodlu, M.; Raoof, A.; Sweijen, T.; van Genuchten, M. T. Effects of sand compaction and mixing on pore structure and the unsaturated soil hydraulic properties. Vadose Zone J. 2016, 15, 1-11.

(41) Boudreau, B. P. The physics of bubbles in surficial, soft, cohesive sediments. Mar. Pet. Geol. 2012, 38, 1-18.

(42) Gauglitz, P. A.; Radke, C. J. Dynamics of Haines jumps for compressible bubbles in constricted capillaries. AIChE J. 1989, 35, 230-240.

(43) Jain, A. K.; Juanes, R. Preferential mode of gas invasion in sediments: grain-scale mechanistic model of coupled multiphase fluid flow and sediment mechanics. J. Geophys. Res.: Solid Earth 2009, 114, No. B08101.

(44) Washburn, E. W. The Dynamics of Capillary Flow. Phys. Rev. 1921, 17, 273-283.

(45) Sherwood, D. J.; Eduardo Sáez, A. The start of ebullition in quiescent, yield-stress fluids. Nucl. Eng. Des. 2014, 270, 101-108.

(46) Pitois, O.; Buisson, M.; Chateau, X. On the collapse pressure of armored bubbles and drops. Eur. Phys. J. E 2015, 38, 1-7. 
(47) Legagneux, L.; Domine, F. A mean field model of the decrease of the specific surface area of dry snow during isothermal metamorphism. J. Geophys. Res.: Earth Surf. 2005, 110, 1-12.

(48) Lazaro, A.; van de Griend, M.; Brouwers, H.; Geus, J. Sacrococcygeal chordoma: Magnetic resonance imaging and computed tomography. Microporous Mesoporous Mater. 2013, 181, 254261.

(49) Lifshitz, I.; Slyozov, V. V. The kinetics of precipitation from supersaturated solid solutions. J. Phys. Chem. Solids 1961, 19, 35-50.

(50) Boudreau, B. P.; Gardiner, B. S.; Johnson, B. D. Rate of growth of isolated bubbles in sediments with a diagenetic source of methane. Limnol. Oceanogr. 2001, 46, 616-622.

(51) Wheeler, S.; Sham, W.; Thomas, S. Gas pressure in unsaturated offshore soils. Can. Geotech. J. 1990, 27, 79-89.

(52) Winterwerp, J. C.; van Kesteren, W. G. M. Introduction to the Physics of Cohesive Sediment Dynamics in the Marine Environment; Developments in Sedimentology; Elsevier: Amsterdam, 2004; Vol. 56, pp 397-423.

(53) Mughrabi, H. Plastic Deformation and Fracture of Materials; Materials Science and Technology, 1992; Vol. 6, pp 2-16.

(54) Johnson, B. D.; Barry, M. A.; Boudreau, B. P.; Jumars, P. A.; Dorgan, K. M. In situ tensile fracture toughness of surficial cohesive marine sediments. Geo-Mar. Lett. 2012, 32, 39-48.

(55) Yang, S. L.; Kvalstad, T. Crack Formation Due to Gas Expansion and Fracture Toughness 640 of a Marine Clay. Proceedings of the Twentieth International Offshore and Polar Engineering Conference, Beijing, 2010; pp 142-147.

(56) Katsman, R.; Ostrovsky, I.; Makovsky, Y. Methane bubble growth in fine-grained muddy aquatic sediment: insight from modeling. Earth Planet. Sci. Lett. 2013, 377-378, 336-346.

(57) Sofrá, F.; Boger, D. V. Environmental rheology for waste minimisation in the minerals industry. Chem. Eng. J. 2002, 86, 319330.

(58) Shin, H.; Santamarina, C. J. Fluid-driven fractures in uncemented sediments: Underlying particle-level processes. Earth Planet. Sci. Lett. 2010, 299, 180-189.

(59) Barry, M. A.; Johnson, B. D.; Boudreau, B. P.; Law, B. A.; Page, V. S.; Hill, P. S.; Wheatcroft, R. A. Sedimentary and geo-mechanical properties of Willapa Bay tidal flats. Cont. Shelf Res. 2013, 60, S198S207.

(60) Crank, J. The Mathematics of Diffusion; Oxford University Press: London, 1979. 